\title{
Conditions under which Male-to-Male Aggression Compromises Cooperation in a Game without Learning
}

\author{
Yutaka Saito*, $^{* 1}$ and Takenori Takada ${ }^{2}$ \\ ${ }^{1}$ Lab. Animal Ecology, Research Institute of Agriculture, Hokkaido University, Japan \\ ${ }^{2}$ Lab. Mathematical Ecology, Graduate School of Earth Environmental Science, Hokkaido Universit, Japan
}

\begin{abstract}
Aggression and cooperation have been the source of many ethology and sociobiology related discussions which have in turn lead to the development of several important models, such as the hawk-dove, cooperator's dilemma and snow-drift games. As these models rarely act in conjunction however, they are considered "separate" means of explaining each phenomenon. Moreover, many of the parameters used in the models are quite abstract and difficult to adapt to actual organisms. By introducing four measurable parameters, the cost of aggression, relatedness, mutual helping and one-sided helping effects into the basic hawk-dove game and limiting the situation to a non-repeated (non-learning) game, we could showed a mixed ESS of aggression and cooperation, which must appear continuous variation of aggressiveness with relatedness in nature. Furthermore, the ESS conditions under which aggression, snow-drift, cooperation and 'altruism' occur, can be expressed in a single pay-off matrix.
\end{abstract}

Keywords: Behavior variation, game theory, spider mite, sociality.

\section{INTRODUCTION}

Cooperation and aggression have attracted many people, and numerous studies [1-8] have been reported since Darwin [9] first expended considerable effort outlining them. Maynard Smith [10] distinguished five processes under which such social behaviours evolved: (i) individual selection, (ii) interdemic selection, (iii) kin selection, (iv) synergistic effects and (v) altruism. It is difficult to deny that aggression is mostly concerned with the process of (i). Cooperation however, has been treated as something like a synonym of altruism [11], and there has been much debate about which process (among from ii to $\mathrm{v}$ ) it originated from [5-8]. Amongst these four processes, kin selection is now thought to be the most important and strongest process for the evolution of cooperation $[11,12]$, and the cooperation is generally considered to be a phenomenon understandable from the relatedness of the interactors [2,5], although there are several contradictory arguments to this [13].

Male-to-male competition to get mates is one such phenomenon and due to the egoistic nature of males, aggression usually prevails in most cases. However, as first revealed by Hamilton [2] several fig wasp species having wingless males show variation in aggressiveness among species. Furthermore, Saito [5] observed clinal variation in male aggressiveness among populations of a social spider mite (Stigmaeopsis miscanthi lives in multi-chambered web nests and males show paternal defense). Such kinds of variation are extraordinary considering the competitive nature of males [14, 15], and have been explained by differences in relatedness between males $[2,5]$.

\footnotetext{
*Address correspondence to this author at the Lab. Animal Ecology, Research Institute of Agriculture, Hokkaido University, Sapporo 060-8589, Japan; E-mail: yutsat@ res.agr.hokudai.ac.jp
}

However, mathematical formulations that can sufficiently explain both how and under what conditions male aggressiveness gradually changes with relatedness are lacking. Hamilton's rule [16] is considered to be a contender [7], even though it only shows the conditions under which solitary (non-cooperative) traits undergo absolute change to cooperation (or altruism). Saito and Mori [17] also provided another line of reasoning about the relationships between aggression, cooperation and relatedness in paired games, but they could only determine the threshold at which aggression unqualifiedly changes into cooperation through changes in relatedness and synergistic effects. Whether there are conditions under which a 'continuous and gradual variation' of aggressiveness occurs in male-to-male interactions has not been strictly determined thus so far.

Saito and Sahara [18] considered that the clinal variation in male-to-male aggressiveness observed in S. miscanthi must be caused by two factors, i.e. differences in male relatedness and differences in the benefit(s) of cooperation for males. If there are any benefit(s) of "cooperation" between males, then the dual questions of how relatedness affects aggression and/or cooperation and why male aggressiveness continuously decreases with relatedness are in urgent need of theoretical resolution. Here we provide a simple nonrepeated (thus non-learning) game model with realistic parameters, which could explain the existence of continuous clinal variation of aggression and cooperation in S. misanthi $[5,18]$, and thereby determine the varying intensity of the parameters. We will also try to assess the relationships beween the present model and several previous models, such as the hawk-dove game with kinship effect and snow-drift model.

\section{ESS OF GAME}

We first focused on haploid organisms in order to avoid any of the inconsistencies that arise between genotype and 
phenotype when applying game theory to diploid inheritance $[19,20,21]$ and for the convenience of simplification (note that $S$. miscanthi males are actually haploid [5]). The situations and the contents of the pay-off matrix are as follows:

1. A symmetrical and non-repeated game without learning occurs between two males in a patch (e.g. woven nest) for a constant number of females (= their offspring). All individuals are included in the paired games.

2. Only two strategies, cooperation (hereafter simply called C strategy) and aggression (called A strategy) exist.

3. We assume that $\mathrm{A}$ and $\mathrm{C}$ strategies are not fixed for an individual, so that the individual plays the A strategy at frequency $q$ and the $\mathrm{C}$ strategy at $1-q$. An individual adopting an A strategy in a game is called an $\mathrm{A}$ strategist and that adopt a $\mathrm{C}$ strategy is called a $\mathrm{C}$ strategist for simplification. We do not address the case in which pure $\mathrm{A}$ and pure $\mathrm{C}$ strategists exist as polymorphisms in the population, because the solution is too complex to describe here.

4. Fitness is estimated by how many offspring the two player males can raise in the next generation. In other words, the resources for which they are competing are represented as the number of surviving offspring (thus forming an evolutionary game).

5. The pay-off matrix of the basic game is as follows;

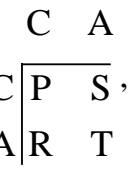

C strategists cooperate in the defence of young in a patch regardless of the confronter's strategy. When a $\mathrm{C}$ strategist interacts with another $\mathrm{C}$ strategist, the net fitness is an additive benefit, and $s(s \geq 0$, hereafter called the mutual helping (cooperation) effect) is shared equally between the two $\mathrm{C}$ strategists who defend their offspring, i.e., the payoff is represented by $\mathrm{P}=\frac{1+s}{2}$. We designed $\mathrm{P}$ so as to express conditions under which the resources available for the interactors in a patch are constant and shareable, as per the following example. If two males interact together in a patch with a constant number of females (mating partners), one of the behavioral traits of such males is to equally share one half of the partners (1/2). In such a case, if males have an ability to defensively protect the patch (including partners and offspring) from natural enemies, then $s>0$ as reported by Saito [22, 23]. The mutual helping effect, $s$ can be measured by comparing the success of paternal defense against predators by two $\mathrm{C}$ strategists with that by a single $\mathrm{C}$ strategist. This $s$ is synonymous with the synergistic coefficient defined by Queller [24].

If a $\mathrm{C}$ strategist interacts with an A strategist, it always loses its direct fitness and gains nothing (payoff, $S=0$, i.e., no offspring). Although this situation may seem quite severe for the C-strategist, mortal male-male aggression has been known in fig wasp species [2] and spider mite species [5, 23] for some time. If $\mathrm{C}$ strategists retain some direct fitness in such confrontations, the model abruptly becomes complex, such that we will not address such cases here.

If an $\mathrm{A}$ strategist interacts with a $\mathrm{C}$ strategist, it receives a payoff, $\mathrm{R}=1+b$, where $b(\geq 0)$ is an additive effect (we call this a "one-sided helping effect") from the $\mathrm{C}$ strategist to the A strategist. The $b$ represents cooperation by the $\mathrm{C}$ strategist towards the A strategist without any reward. It is not unrealistic to imagine that a $\mathrm{C}$ strategist may play some defensive role(s) in a patch (nest) even though its own mating will be suppressed by an A strategist. As a "one-sided helper" per se, its attendance may be effective in the defence of the A strategist's offspring. This kind of behavior is known in several bird species [6] and a paper wasp species [25].

When an A strategist confronts another A strategist, they always fight. The winning combatant will receive a payoff of $\mathrm{T}=\frac{1-k}{2}$, where $k(0 \leq k \leq 1)$ is the winner's risk of injury (fitness loss) through aggression. The loser is always killed by the winner as is known in S. miscanthi [5]. The variable $k$ is simply the cost of aggression that was originally defined in the hawk-dove game [26] and can be measured as the probability of winnter's death or injury in an aggressive confrontation between A strategists.

6. Because kin selection is thought to be a major driving force in the evolution of animal behaviour [7, 10, 12, 26], we introduced the mean relatedness between confronting individuals, $r$ ( $0 \leq r \leq 1$, Wright's coefficient of relatedness), into the previously defined matrix to produce an inclusive fitness matrix (note that this matrix is only valid under assumption $3[19,27])$ :

$$
\begin{aligned}
& \text { C A }
\end{aligned}
$$

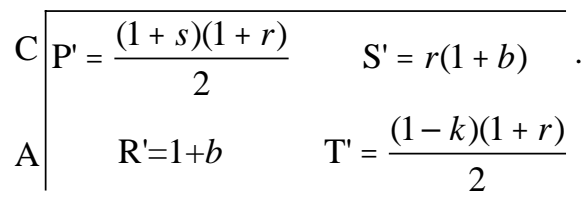

According to the methods of Hines and Maynard Smith [28], Grafen [27] and Maynard Smith [19], the mixed ESS (evolutionary stable strategy), $q^{*}$ (frequency of adopting the A strategy, $\left.0 \leq q^{*} \leq 1\right)$ is expected to be:

$q^{*}=\frac{(\mathrm{R}-\mathrm{P})+r(\mathrm{~S}-\mathrm{P})}{(1+r)(\mathrm{R}+\mathrm{S}-\mathrm{T}-\mathrm{P})}$ from the basic payoff matrix.

Therefore

$q^{*}=\frac{1+2 b-r-s-r s}{(1+r)(2 b+k-s)}$

Focusing on the relatedness, we examined the condition that $q^{*}$ actually attains a mixed ESS; the relevant conditions are when $\mathrm{S}^{\prime}>\mathrm{T}^{\prime}$ and $\mathrm{R}^{\prime}>\mathrm{P}^{\prime}$ (Bishop-Cannings theorem; [19]). Therefore, $\mathrm{S}^{\prime}+\mathrm{R}^{\prime}>\mathrm{T}^{\prime}+\mathrm{P}^{\prime}$ means $2 b+k-s>0$ (the same as Grafen's condition [27], see Appendix 1). Using these relationships, we obtained 


$$
\frac{1-k}{1+k+2 b}<r<\frac{1-s+2 b}{1+s}
$$

under $2 b+k-s>0$ when we focused on the condition of $r$. So, the mixed strategy $\left(0<q^{*}<1\right)$ reaches an ESS, where 1 $s+2 b>0$ is the necessary condition for the existence of positive $r$.

\section{DISCUSSION}

\section{Details of Mixed Strategy}

We then learned that conditions exist under which pure (when $r \leq \frac{1-k}{1+k+2 b}$ or $r \geq \frac{1-s+2 b}{1+s}$ ) and mixed strategies (Eq. 2, when $2 b+k-s>0$ and $1-s+2 b>0$, but this is always satisfied when $2 b+k-s>0$ at $0 \leq k \leq 1$ ) reach an ESS. However, Fig. (1) shows that the complexity of the ESS depends upon its parameter values. The basic conditions are further divided into two cases mainly depending upon the $b$ and $s$ values (Fig. 1): A: $b \leq s$. B: $b>s$ (see Appendix 2).
In case $\mathrm{A}$, on the one hand, the mixed strategy reaches an ESS at $q^{*}$, when $\mathrm{P}^{\prime}>\mathrm{S}^{\prime}$, i.e. inequality (2) and the relationship between pay-off values (Fig. 1) becomes $\mathrm{R}^{\prime}>\mathrm{P}^{\prime}>\mathrm{S}^{\prime}>$ $\mathrm{T}^{\prime}$. This relationship corresponds to the snow-drift model $[6,29,30]$, which explains the occurrence of "non-kin" cooperation. Note that such a relationship can also be realized here in the hawk-dove game by introducing $k, r$, and $s$, although considerable differences exist in the parameters hypothesized in the original snow-drift model.

In case $\mathrm{B}$, on the other hand, the mixed strategy reaches an ESS both when $\mathrm{R}^{\prime}>\mathrm{P}^{\prime}>\mathrm{S}^{\prime}>\mathrm{T}^{\prime}$ and when $\mathrm{R}^{\prime}>\mathrm{S}^{\prime}>\mathrm{P}^{\prime}>$ $\mathrm{T}^{\prime}$ (Fig. 1), whereas the pure $\mathrm{C}$ strategy condition $\left(\mathrm{P}^{\prime}>\mathrm{R}^{\prime}>\right.$ $\left.\mathrm{S}^{\prime}>\mathrm{T}^{\prime}\right)$ disappears. The $\mathrm{R}^{\prime}>\mathrm{S}^{\prime}>\mathrm{P}^{\prime}>\mathrm{T}^{\prime}$ relationship may be the first step in the evolutionary game model approach, although it was known as "leader's model" in economics.

How the ESS (frequency of A strategy, $q^{*}$ ) varies with the four parameters is shown for four cases in Fig. (2). If no effect of one-sided helping $(b=0)$ and a low risk of aggression $(k=0.3)$ exist, then three ESS types, namely, pure A strategy, mixed strategy, and pure $\mathrm{C}$ strategy, can become ESS's depending upon the $r$ values at every $s$ value satisfying $2 b+k-s>0$ (in Fig. (2-1), also see Fig. 1).

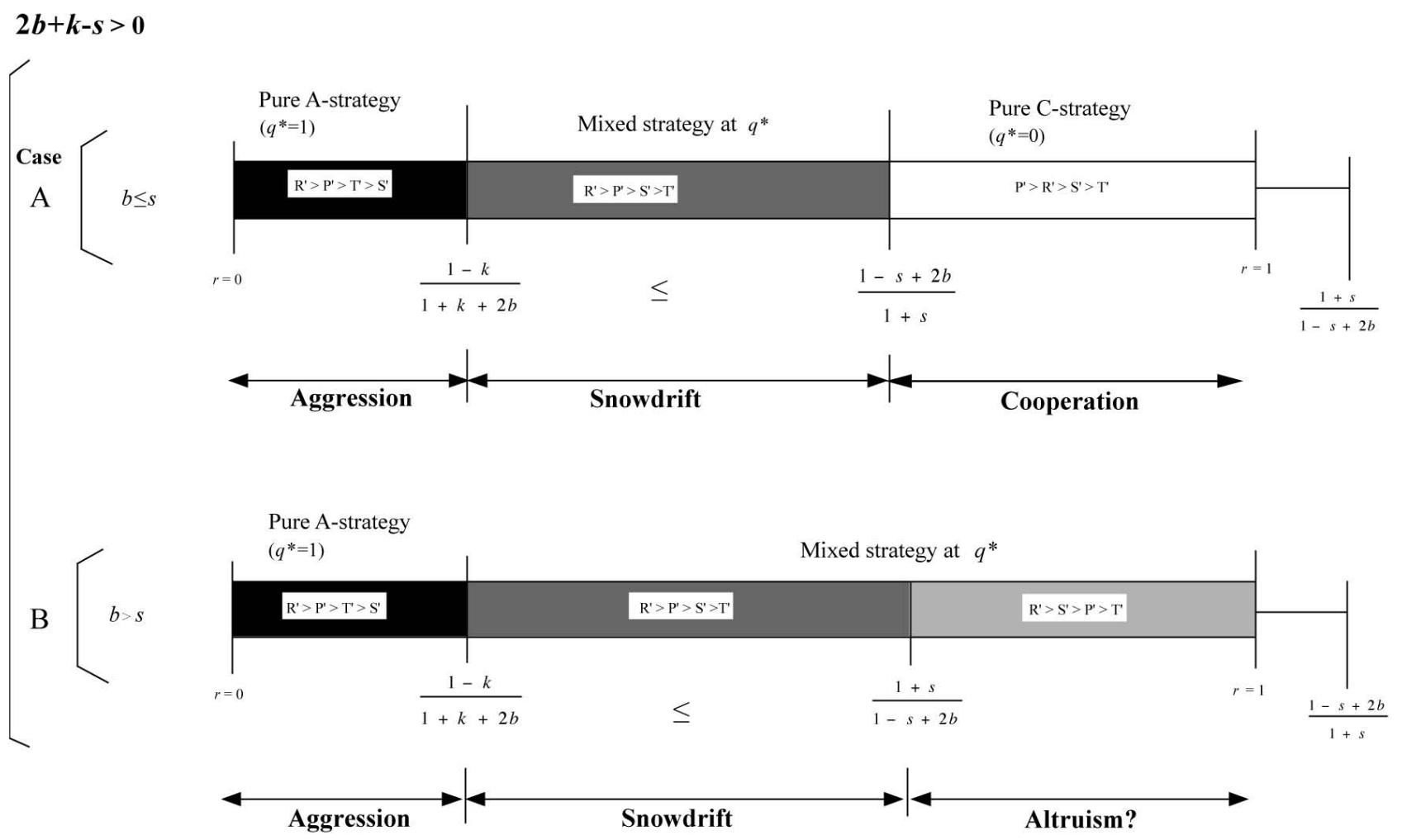

Fig. (1). Relationship under $2 b+k-s>0$ among the parameters of the inclusive fitness model and ESS strategies. $r(0 \leq r \leq 1)$ is Wright's coefficient of relatedness, $k(0 \leq k \leq 1)$ is the risk of injury (fitness loss) through aggression, $b(0 \leq b \leq 1)$ is the cooperation effect of $\mathrm{C}$ strategist to A strategist without any rewards, and $s(0 \leq s)$ is the additive benefit of cooperation by two $\mathrm{C}$ strategists who defend or feed their offspring. $\mathrm{P}^{\prime}, \mathrm{S}^{\prime}, \mathrm{T}^{\prime}$ and $\mathrm{R}^{\prime}$ are pay-off values of the inclusive fitness matrix;

$$
\begin{aligned}
& \text { C A }
\end{aligned}
$$

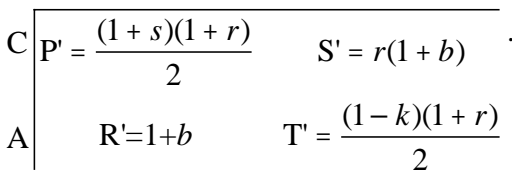


In the case of S. miscanthi, Saito [5] observed very strong confrontations between males, such that the value $k=0.3$ (namely that $30 \%$ of winning males will die after two Astrategists face off) is probable (Saito, unpublished). Furthermore, the $s$ value (mutual helping effect) was estimated to be around $s=0.25$ in an experimental study (Yano and Saito, unpublished). From these two parameters, we could learn that male aggressiveness gradually changes with $r$-value as shown by the solid-white line within the range from ca. $r=0.5$ to 0.6 in Fig. (2-1).

If $b=0.5$ and $k=0.3$, the white line drawn in Fig. (2-2) separates two cases, i.e., cases A and B in Fig. (1). If $s \geq b$, the ESS is similar to Fig. (2-1), but if $s<b$, then the pure C strategy disappears, and only the pure A and the mixed strategies achieve ESS status (Fig. (2-2)). The area enclosed by the thick-black curved line (when $\mathrm{R}^{\prime}>\mathrm{S}^{\prime}>\mathrm{P}^{\prime}>\mathrm{T}^{\prime}$ in Fig. (1) and Fig. (2-2), (3)) represents an ESS in which the inclusive fitness of a $\mathrm{C}$ strategist is higher when interacting with an A strategist (i.e. $\left.\mathrm{S}^{\prime}\right)$ than with another $\mathrm{C}$ strategist $\left(\mathrm{P}^{\prime}\right)$. $\mathrm{S}^{\prime}$ $>\mathrm{P}^{\prime}$ occurs only when $r$ is higher in case $\mathrm{B}$ of Fig. (1). This is unusual status, beause a $\mathrm{C}$ strategist is expected to achieve higher fitness when encountering an A strategist. This is a kinship effect because it does not occur when $r=0$. In Fig. (2-3), a similar pattern appears even when $k=0$, showing that $k$ only serves to increase the ESS area of the pure A strategy. On the other hand, if there is no helping effect $(s=0)$, pure C strategy never reaches an ESS, while both the pure A and mixed strategies (Fig. 1-B, thus including both $\mathrm{S}^{\prime}>\mathrm{P}^{\prime}$ and $\left.\mathrm{S}^{\prime}<\mathrm{P}^{\prime}\right)$ can attain an ESS.

\section{Hawk-Dove Game}

Let's examine the relationship between the present and previous models. The basic hawk-dove game is obtained when $s=0, b=0$ and $r=0$ in the present model. In this game, a necessary condition under which a mixed strategy attains an ESS is $\mathrm{S}^{\prime}>\mathrm{T}^{\prime}$, such that "the benefit" < "cost" is required for achiving a mixed ESS at a hawk vs. hawk confrontation. This is realized when $k>1$, then $\mathrm{T}^{\prime}<0$ [19]. In the context of the present game, however, $\mathrm{T}^{\prime}<0$ is unrealistic because the minimum fitness of an individual is always 0 . Therefore, the pure hawk strategy (i.e. A strategy) is only an ESS in the evolutionary model of the simple hawk-dove game.

On the other hand, if kinship effects are introduced $(s=0$, $b=0$ and $r>0$ [28]) into the evolutionary hawk-dove game, $\mathrm{S}^{\prime}>\mathrm{T}^{\prime}$ could be realized when $r>\frac{(1-k)(1+r)}{2}$. then $r>\frac{1-k}{1+k}$. Therefore, $r$ which satisfies the latter condition exists. Furthermore, the other condition of the BishopCannings theorem could be satisfied when $r<1$. Thus, there

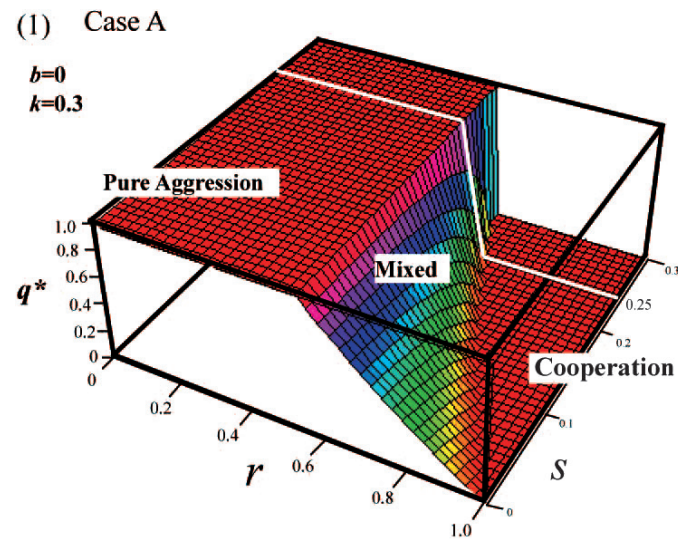

(3) Cases A \& B

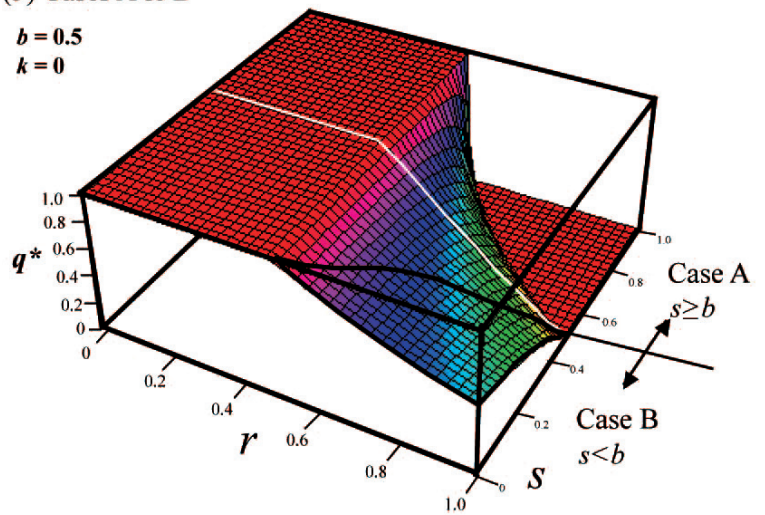

(2) Cases A \& B

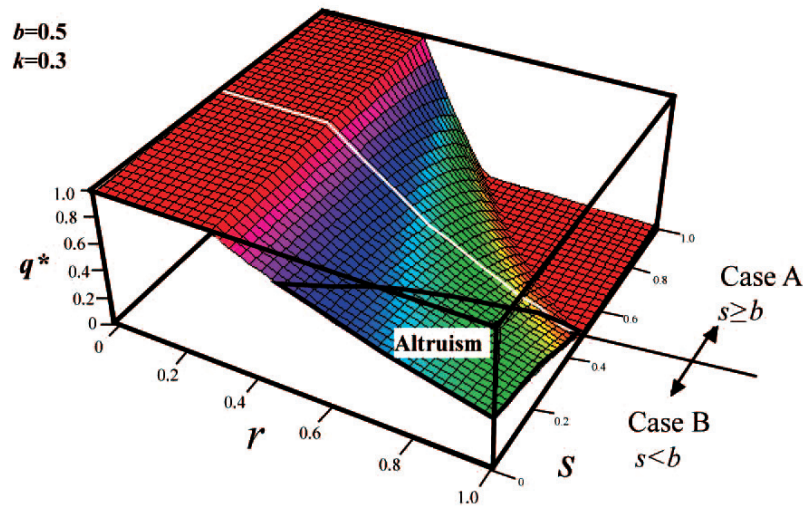

(4) Case B

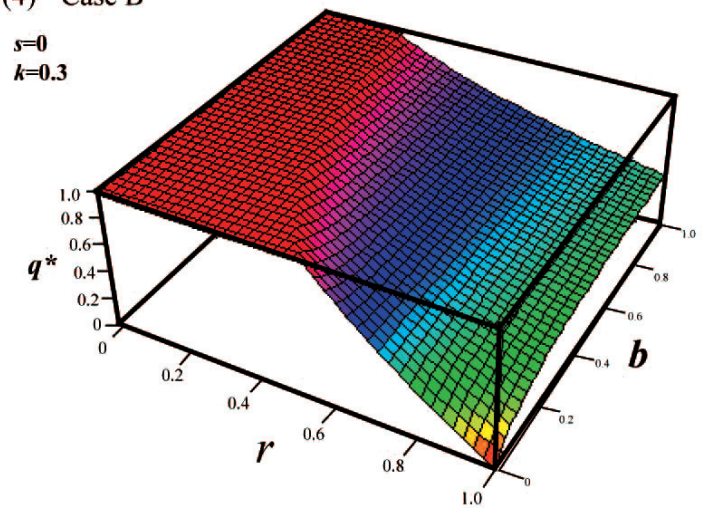

Fig. (2). Simulated ESS (frequency $q^{*}$ of A strategy) surfaces with various $r$ and $s$ or $b$. Variables and cases are the same as in Fig. (1). White line drawn in (1) is when $s=0.25$ and those in (2) and (3) are the thresholds of case A and B. ESS areas enclosed by a curved black line in (2) and (3) show "altruism" areas on which the inclusive fitness of a $\mathrm{C}$ strategist is higher when interacting with an A strategist than with another $\mathrm{C}$ strategist. 
is an ESS for pure A strategy as well as for the mix of A and $\mathrm{C}$ strategies, depending upon $k$ and $r$ values. This means that aggressiveness will vary with the relatedness $(r)$ between players and the risk of injury $(k)$ without $s$ and $b$ effects. Such a situation was shown by Maynard Smith [19] and may correspond to the case that Hamilton [2] hypothesized in the fig wasp case (though West et al. [7] provided an alternative explanation).

Because the original hawk-dove game with kinship effect can attain a pure $\mathrm{C}$ strategy (i.e. $q^{*}=0$ ) only when $r=1$ under $s=0$ and $b=0$ conditions, finding an area in which the pure $\mathrm{C}$ strategy is an ESS when $r<1$ (if we focus on the mutual cooperation effect $s>0$ ) must be of importance. The conditions mentioned above are re-defined as follows: When $\mathrm{R}^{\prime}>\mathrm{P}^{\prime}>\mathrm{T}^{\prime}>\mathrm{S}^{\prime}$, the pure A strategy is an ESS. When $\mathrm{R}^{\prime}>\mathrm{P}^{\prime}$ $>\mathrm{S}^{\prime}>\mathrm{T}^{\prime}$, the mix of A and $\mathrm{C}$ strategies (A strategy at the frequency of $q^{*}$ ) is an ESS. Furthermore, when $\mathrm{P}^{\prime}>\mathrm{R}^{\prime}>\mathrm{S}^{\prime}>$ $\mathrm{T}^{\prime}$, the pure $\mathrm{C}$ strategy is an ESS.

In relation to the above, Saito and Mori [17] showed that the threshold at which mutual cooperation evolves as $(1+s)(1+r)>2$. It should be noted that the conditions, $s>$ $0, b=0$ and $r>\frac{1-s}{1+s}$ under which pure $C$ strategy reaches an ESS are exactly the same as Saito and Mori's [17] conditions for the evolution of mutual cooperation (in the sense of pure C strategy).

The importance of mutual helping effect or cooperation in the evolution of social insects has been emphasized $[25,31]$. The present model indicated that 'aggression' compromises 'cooperation' depending upon $s$ even if the relatedness is nearly zero. The fact that cooperative socialities are observed not only between relatives, but also between nonrelatives [25] corresponds well to the present conclusion.

\section{Snow Drift Game}

The relationship between the pay-off values, $\mathrm{R}^{\prime}>\mathrm{P}^{\prime}>\mathrm{S}^{\prime}$ $>\mathrm{T}^{\prime}$ (Fig. 1) is known as the "snow drift model" (S-D model hereafter), which explains the occurrence of cooperation $[6,29,30]$ without kinship. Thus, the S-D model is a part of the present model. It is important to note that relatedness $(r)$ has never been considered in the previous S-D model. By introducing $r$, the $\mathrm{R}^{\prime}>\mathrm{P}^{\prime}>\mathrm{S}^{\prime}>\mathrm{T}^{\prime}$ condition can be realized in the present model, even if there is no cooperation effect ( $s$ $=0$ ). There is an important difference between the S-D and the present model situations; the former focuses only on the evolution of cooperation (therefore, the defector's fitness $=0$ ), whereas the latter simultaneously focuses on the evolution of both aggression and cooperation. Therefore, the pay-off relationship $\mathrm{R}^{\prime}>\mathrm{P}^{\prime}>\mathrm{S}^{\prime}>\mathrm{T}^{\prime}$ (known as the ESS condition of mixed strategy of defector and cooperator in the S-D model), is also realized in the hawk-dove game with kinship effect $(r>0)$ and without cooperation effect $(s=0)$.

\section{A Mixed Strategy or Altruism?}

In the present model, we introduced the one-sided helping effect, $b$ as an additive effect, When $b \geq 0$, the pay-off relationship becomes $\mathrm{R}^{\prime}>\mathrm{S}^{\prime}>\mathrm{P}^{\prime}>\mathrm{T}^{\prime}$, if $b>s$ (Fig. 1-B). As stated previously, pure mutual cooperation reaches an ESS when $\mathrm{P}^{\prime}>\mathrm{R}^{\prime}>\mathrm{S}^{\prime}>\mathrm{T}^{\prime}$, and the mix of aggression and cooperation reaches an ESS when $\mathrm{R}^{\prime}>\mathrm{P}^{\prime}>\mathrm{S}^{\prime}>\mathrm{T}^{\prime}(\mathrm{S}-\mathrm{D}$ model) and $\mathrm{R}^{\prime}>\mathrm{S}^{\prime}>\mathrm{P}^{\prime}>\mathrm{T}^{\prime}$. What is the meaning of the mix of $A$ and $\mathrm{C}$ strategies in the last case? $\mathrm{S}^{\prime}>\mathrm{P}^{\prime}$ means that the fitness of a $\mathrm{C}$ strategist is higher when interacting with an $\mathrm{A}$ strategist than with another C strategist, because its onesided helping effect $(b)$ is sufficiently high in comparison with its cooperative effect, $s$. It may look like the situation known in eusocial species, in which reproductive (analogus to A strategist in the present model) and non reproductive (also to $\mathrm{C}$ strategist) castes evolved. It is generally called as 'altruism' and considered to be a pattern of mixed strategy in the present model.

As such we can bridge from one behavioural extreme to another, i.e. 'aggression' to 'cooperation' in a continuous manner and show that the clinal variation in aggression and cooperation observed in a social spider mite $[5,18]$ is likely a result of compromise, namely the ESS of mixed strategy depends upon $b, r, k$ and $s$ (Figs. 1 and 2). This means that aggressive and cooperative behaviors are not alternative, but can exist simultaneously in a single individual.

\section{ACKNOWLEDGMENTS}

I thank J.C. Choe, K. Ito, Y. Ito, Y. Iwasa, Y. Kamimura, N. Kumano, K. Mori, N. Ohsaki, D.C. Queller, T. Sakagami, Y. Sato, K. Tsuji, N. Tsuji, S. West, and N. Yamamura for discussion and comments; A.R. Chittenden for discussion and English revision; The editor and two anonymous reviewers from American Naturalist for their critical comments on the preliminary version. This study was supported by Grants-in Aid for Scientific Research (KAKENHI: A17207003, B-20370006 and C-19570011) from the Japan Society for the Promotion of Science, and by MEXT through Special Coordination Funds for Promoting Science and Technology, Japan, titled "Hokkaido University Sustainability Governance Project."

\section{APPENDIX 1}

Grafen (1979) proposed a necessary condition for the $I$ strategist (adopting A-strategy at frequency $q^{*}$ ) to be an ESS when he constructed the Hawk-Dove game between relatives (Maynard Smith 1980):

$\mathrm{E}(I, I) \geq r^{\prime} \mathrm{E}(M, M)+\left(1-r^{\prime}\right) \mathrm{E}(M, I)$,

where $I$ is a candidate strategy of ESS, $M$ is a rare mutant strategy adopting A-strategy at the frequency $m$, and $r^{\prime}$ is the probability that two players will be identical by descent. Here, 


$$
\begin{aligned}
& \mathrm{E}(I, I)=\left\{\frac{1+2 b-r-s-r s}{(1+r)(2 b+k-s)}\right\}^{2} \frac{1-k}{2}+\frac{1+2 b-r-s-r s}{(1+r)(2 b+k-s)}\left\{1-\frac{1+2 b-r-s-r s)}{(1+r)(2 b+k-s)}\right\}(1+b), \\
& +\frac{1+2 b-r-s-r s}{(1+r)(2 b+k-s)}\left\{1-\frac{1+2 b-r-s-r s}{(1+r)(2 b+k-s)}\right\} \cdot 0+\left\{1-\frac{1+2 b-r-s-r s}{(1+r)(2 b+k-s)}\right\}^{2} \frac{1+s}{2} \\
& \mathrm{E}(M, I)=m\left\{\frac{1+2 b-r-s-r s}{(1+r)(2 b+k-s)}\right\} \frac{1-k}{2}+m\left\{1-\frac{1+2 b-r-s-r s}{(1+r)(2 b+k-s)}\right\}(1+b) \\
& +\frac{1+2 b-r-s-r s}{(1+r)(2 b+k-s)}(1-m) \cdot 0+\left\{1-\frac{1+2 b-r-s-r s}{(1+r)(2 b+k-s)}\right\}(1-m) \frac{1+s}{2}
\end{aligned}
$$

and

$$
\begin{aligned}
& \mathrm{E}(M, I)=m^{2} \frac{1-k}{2}+m(1-m)(1+b) \\
& +m(1-m) \cdot 0+(1-m)^{2} \frac{1+s}{2}
\end{aligned}
$$

Substituting Eqs. (A2-4) into Eq. (A1), we obtained Grafen's necessary condition in our model:

$\mathrm{E}(I, I)-r^{\prime} \mathrm{E}(M, M)-\left(1-r^{\prime}\right) \mathrm{E}(M, I)$

$$
=\frac{r\{k m r+k m+r-1+2 b(m r+m-1)-s(m-1)(1+r)\}^{2}}{2(1+r)^{2}(2 b+k-s)} \geq 0 \text { at } 0 \leq r=r^{\prime} .
$$

It means $2 b+k-s>0$.

On the other hand, the necessary and sufficient conditions for the existence of mixed strategy are

$\mathrm{S}^{\prime}>\mathrm{T}^{\prime} r(1+2 b+k)>1-k$

and

$\mathrm{R}^{\prime}>\mathrm{P}^{\prime} 1+2 b-s>r(1+s)$

Summing up Eqs. (A5 and 6), we obtained $(1+r)(2 b+k-s)>0$. Therefore, $2 b+k-s>0$ when the mixed strategy exists. Grafen's condition, $2 b+k-s>0$ is the same as the condition detected by Bishop-Cannings.

From Eq. (1) in the text, $q^{*}=\frac{1+2 b-r-s-r s}{(1+r)(2 b+k-s)}$. When $q^{*}>0,1+2 b-r-s-r s>0$ since $2 b+k-s>0$, i. e. $r<\frac{1-s+2 b}{1+s}$. When $q^{*}<1,1+2 b-r-s-r s<(1+r)(2 b+k-s)$ since $2 b+k-s>0$, i. e. $\frac{1-k}{1+k+2 b}<r$.

We obtained Eq. (2), which is the condition of relatedness for the existence of the mixed strategy.

\section{APPENDIX 2}

The mixed strategy condition, $\mathrm{S}^{\prime}>\mathrm{T}^{\prime}$ and $\mathrm{R}^{\prime}>\mathrm{P}^{\prime}$, restricts the order of combinations among $\mathrm{S}^{\prime}, \mathrm{T}^{\prime}, \mathrm{R}^{\prime}$ and $\mathrm{P}^{\prime}$. There are 6 combinations:
1) $\quad \mathrm{R}^{\prime}>\mathrm{P}^{\prime}>\mathrm{S}^{\prime}>\mathrm{T}^{\prime}$
2) $\quad \mathrm{R}^{\prime}>\mathrm{S}^{\prime}>\mathrm{P}^{\prime}>\mathrm{T}^{\prime}$
3) $\quad \mathrm{R}^{\prime}>\mathrm{S}^{\prime}>\mathrm{T}^{\prime}>\mathrm{P}^{\prime}$
4) $\quad \mathrm{S}^{\prime}>\mathrm{R}^{\prime}>\mathrm{T}^{\prime}>\mathrm{P}^{\prime}$
5) $\quad \mathrm{S}^{\prime}>\mathrm{T}^{\prime}>\mathrm{R}^{\prime}>\mathrm{P}^{\prime}$
6) $\quad \mathrm{S}^{\prime}>\mathrm{R}^{\prime}>\mathrm{P}^{\prime}>\mathrm{T}^{\prime}$

In our model, the third combination is removed because $\mathrm{P}^{\prime}=\frac{(1+s)(1+r)}{2}>\frac{(1-k)(1+r)}{2}=\mathrm{T}^{\prime}$, and the last 3 combinations are removed because $\mathrm{R}^{\prime}=1+b>r(1+b)=\mathrm{S}^{\prime}$. Therefore, depending on the relationship between $\mathrm{P}^{\prime}$ and $\mathrm{S}^{\prime}$ only 2 combinations remain: 
$\mathrm{S}^{\prime}>\mathrm{P}^{\prime}$ means $r>\frac{1+s}{1-s+2 b}$

(This corresponds to Case B) and

$\mathrm{P}^{\prime}>\mathrm{S}^{\prime}$ means $r<\frac{1+s}{1-s+2 b}$

(This corresponds to Case A)

When $s \geq b$, the right-hand side of (A7) exceeds 1 and Case B) $\mathrm{R}^{\prime}>\mathrm{S}^{\prime}>\mathrm{P}^{\prime}>\mathrm{T}^{\prime}$ does not occur. The upper threshold of relatedness, $\frac{1-s+2 b}{1+s}$, is less than 1 .

When $b>s$, the upper threshold of relatedness exceeds 1 and pure C-strategy disappears, where both Case 1) $\mathrm{R}^{\prime}>\mathrm{P}^{\prime}>\mathrm{S}^{\prime}>$ $\mathrm{T}^{\prime}$ and Case 2) $\mathrm{R}^{\prime}>\mathrm{S}^{\prime}>\mathrm{P}^{\prime}>\mathrm{T}^{\prime}$ are possible.

\section{REFERENCES}

[1] Wilson, E.O. Sociobiology: The New Synthesis. Harvard University Press: Cambridge, 1975.

[2] Hamilton, W.D. Wingless and fighting males in fig wasps and other insects. In Sexual Selection and Reproductive Competition in Insects.; Blum, M.S.; Blum, N.A., Eds.; Academic Press: New York, 1979; pp. 167-220.

[3] Taylor, P.D. Altruism in viscous populations - an inclusive fitness model. Evol. Ecol., 1992, 6, 352-356.

[4] Queller D.C. Genetic relatedness in viscous populations. Evol. Ecol., 1994, 8, 70-73.

[5] Saito, Y. Clinal variation in male-to-male antagonism and weaponry in a subsocial mite. Evolution, 1995, 49, 413-417.

[6] Dugatkin, L.A. Cooperation among Animals: An Evolutionary Perspective. Oxford University Press: New York, 1997.

[7] West, S.A.; Murray, M.G.; Machado, C.A.; Griffin, A.S.; Herre, E.A. Testing Hamilton's rule with competition between relatives. Nature, 2001, 409, 510-513.

[8] Griffin, A.S.; West, S.A.; Buckling, A. Cooperation and competition in pathogenic bacteria. Nature, 2004, 430, 1024-1027.

[9] Darwin, C. On the Origin of Species.; Murray, J., Ed.; London, 1859.

[10] Maynard S.J. In Current Problems in Sociobiology; King's College Sociobiology Group Cambridge.; Ed., Cambridge University Press: London, 1982; pp. 29-44.

[11] Lehmann, L.; Keller, L. The evolution of cooperation and altruisma general frame work and a classification of models. J. Evol. Biol., 2006, 19, 1365-1376.

[12] Foster K.R.; Wenseleers, T.; Ratnieks F.L.W. Kin selection is the key to altruism. Trends Ecol. Evol., 2005, 21, 57-60.

[13] Wilson, E.O.; Hölldobler, B. Eusociality: origin and consequences. Proc. Natl. Acad. Sci. USA, 2005, 102, 13367-13371.

[14] Hamilton W.D. Altruism and related phenomena, mainly in social insects. Аnпи. Rev. Ecol. Syst., 1972, 3, 193-232.

[15] Saito, Y. Sociality and kin selection in Acari. In The Evolution of Social Behaviour in Insects and Arachnids.; Choe, J.C.; Crespi, B.J. Eds.; Cambridge University Press: Cambridge, 1997; pp. 443457.
[16] Michod R.E.; Hamilton W.D. Coefficient of relatedness in sociobiology. Nature, 1980, 288, 694-697.

[17] Saito, Y.; Mori, K. Where does male-to-male "aggression" compromise "cooperation"? Popul. Ecol., 2005, 47, 159-166.

[18] Saito Y.; Sahara K. Two clinal trends in male-male aggressiveness in a subsocial spider mite (Schizotetranychus miscanthi). Behav. Ecol. Sociobiol., 1999, 46, 25-29.

[19] Maynard, S.J. Evolution and the Theory of Games. Cambridge University Press: Cambridge, 1982.

[20] Queller D.C. Kin selection and frequency dependence: a game theoretical approach. Biol. J. Linn. Soc., 1984, 23, 133-143.

[21] Aoki, K. A quantitative genetic model of two-policy games between relatives. J. Theory Biol., 1984, 109, 111-126.

[22] Saito, Y. Prey kills predator: counter-attack success of a spider mite against its specific phytoseiid predator. Exp. Appl. Acarol., 1986, 2 , 47-62.

[23] Saito, Y. "Harem" and "non-harem" type mating systems in two species of subsocial spider mites (Acari, Tetranychidae). Res. Popul. Ecol., 1990, 32, 1-16.

[24] Queller D.C. Kinship, reciprocity and synergism in the evolution of social behaviour. Nature, 1985, 318, 366-367.

[25] Ito, Y. Behaviour and Social Evolution of Wasps: The communal aggregation hypothesis.; Oxford University Press: Oxford, 1993.

[26] Maynard, S.J. Evolution and theory of games. Am. Sci., 1976, 64, 41-45.

[27] Grafen, A. The hawk-dove game played between relatives. Anim. Behav., 1979, 27, 905-907.

[28] Hines, W.; Maynard, S.J. Games between relatives. J. Theory Biol., 1979, 79, 19-30.

[29] Doebeli, M.; Hauert, C. Models of cooperation based on the prisoner's dilemma and the snow drift game. Ecol. Lett., 2005, 8, 748766.

[30] Sugden, R. The economics of Rights, Co-operation and Welfare. Blackwell: London, 1986.

[31] Lin, N.; Michner, C. D. Evolution of eusociality in insects. Q. Rev. Biol., 1972, 47, 131-159. 